\title{
Calcium dysregulation in atrial fibrillation: the role of CaMKII
}

\author{
Jordi Heijman ${ }^{1}$, Niels Voigt ${ }^{1}$, Xander H. T. Wehrens ${ }^{2}$ and Dobromir Dobrev ${ }^{1}$ * \\ 1 Institute of Pharmacology, Faculty of Medicine, University Duisburg-Essen, Essen, Germany \\ ${ }^{2}$ Cardiovascular Research Institute, Departments of Molecular Physiology and Biophysics, and Medicine-Cardiology, Baylor College of Medicine, Houston, TX, USA
}

\section{Edited by:}

Andrew G. Edwards, Oslo University

Hospital, Norway

Reviewed by:

David R. Van Wagoner, Cleveland Clinic Lerner College of Medicine of Case Western Reserve University, USA

Sandeep Pandit, University of Michigan, USA

Eleonora Grandi, University of California Davis, USA

*Correspondence:

Dobromir Dobrev, Institute of

Pharmacology, Faculty of Medicine, University Duisburg-Essen,

Hufelandstrasse 55, 45122 Essen, Germany

e-mail:dobromir.dobrev@

uk-essen.de
Atrial fibrillation (AF) is the most frequently encountered clinical arrhythmia and is associated with increased morbidity and mortality. Ectopic activity and reentry are considered major arrhythmogenic mechanisms contributing to the initiation and maintenance of AF. In addition, AF is self-reinforcing through progressive electrical and structural remodeling which stabilize the arrhythmia and make it more difficult to treat. Recent research has suggested an important role for $\mathrm{Ca}^{2+}$-dysregulation in AF. $\mathrm{Ca}^{2+}$-handling abnormalities may promote ectopic activity, conduction abnormalities facilitating reentry, and AF-related remodeling. In this review article, we summarize the $\mathrm{Ca}^{2+}$-handling derangements occurring in $\mathrm{AF}$ and discuss their impact on fundamental arrhythmogenic mechanisms. We focus in particular on the role of the multifunctional $\mathrm{Ca}^{2+} /$ calmodulin-dependent protein kinase type-II (CaMKII), which acts as a major link between $\mathrm{Ca}^{2+}$-dysregulation and arrhythmogenesis. CaMKII expression and activity are increased in AF and promote arrhythmogenesis through phosphorylation of various targets involved in cardiac electrophysiology and excitation-contraction coupling. We discuss the implications for potential novel therapeutic strategies for AF based on CaMKII and $\mathrm{Ca}^{2+}$-handling abnormalities.

Keywords: atrial fibrillation, calcium, CaMKII, ectopic activity, reentry

\section{INTRODUCTION}

Atrial fibrillation $(\mathrm{AF})$ is the most prevalent heart-rhythm disorder, estimated to affect more than 33 million people worldwide (Chugh et al., 2013). AF is associated with increased morbidity and mortality, notably as a risk factor for stroke and worsening of heart failure (Camm et al., 2012; Chugh et al., 2013). Current pharmacological treatments for rhythmcontrol of AF mainly include class-I and class-III antiarrhythmic drugs, which have modest efficacy, providing sinus-rhythm maintenance in only $30-70 \%$ of patients after $>1$ year of follow-up (Camm, 2012). In addition, these drugs are associated with substantial adverse side-effects including ventricular proarrhythmia and extra-cardiac toxicity (Zimetbaum, 2012; Heijman et al., 2013a). The AF incidence is expected to increase due to aging of the population, making the development of improved antiarrhythmic treatments of critical importance. A better understanding of AF pathophysiology is expected to foster this development (Dobrev et al., 2012). Accumulating evidence has highlighted a central role for abnormal $\mathrm{Ca}^{2+}$ handling in AF-pathophysiology (Dobrev and Nattel, 2008; Heijman et al., 2012; Nattel and Dobrev, 2012). Here, we review recent studies detailing the proarrhythmic role of AFrelated $\mathrm{Ca}^{2+}$-handling abnormalities, with particular focus on the contributions of the $\mathrm{Ca}^{2+} /$ calmodulin-dependent protein kinase type-II (CaMKII).

\section{ATRIAL CELLULAR ELECTROPHYSIOLOGY AND ARRHYTHMOGENIC MECHANISMS NORMAL ATRIAL CELLULAR ELECTROPHYSIOLOGY AND $\mathrm{Ca}^{2+}$-HANDLING}

The atrial action potential (AP) is determined by depolarizing and repolarizing ionic currents (Dobrev and Ravens, 2003). Depolarizing currents include the cardiac voltage-gated $\mathrm{Na}^{+}$current $\left(\mathrm{I}_{\mathrm{Na}}\right)$ and its persistent ("late") component $\left(\mathrm{I}_{\mathrm{Na}}\right.$,late $)$, the L-type $\mathrm{Ca}^{2+}$-current $\left(\mathrm{I}_{\mathrm{Ca}, \mathrm{L}}\right)$ and the $\mathrm{Na}^{+} / \mathrm{Ca}^{2+}$-exchanger type-1 (NCX1) current $\left(\mathrm{I}_{\mathrm{NCX}}\right)$, which, in its forward mode, extrudes one $\mathrm{Ca}^{2+}$-ion in exchange for $3 \mathrm{Na}^{+}$-ions, resulting in a net depolarizing inward current. Repolarizing currents include the transientoutward $\mathrm{K}^{+}$-current $\left(\mathrm{I}_{\mathrm{to}}\right)$, delayed-rectifier $\mathrm{K}^{+}$-currents with slow, rapid or ultra-rapid kinetics $\left(\mathrm{I}_{\mathrm{Ks}}, \mathrm{I}_{\mathrm{Kr}}\right.$, and $\mathrm{I}_{\mathrm{Kur}}$, respectively), as well as the $\mathrm{Na}^{+} / \mathrm{K}^{+}$-ATPase current $\left(\mathrm{I}_{\mathrm{NaK}}\right)$. In addition, AP duration (APD) and resting membrane potential are influenced by basal and acetylcholine-activated inward-rectifier $\mathrm{K}^{+}$-currents ( $\mathrm{I}_{\mathrm{K} 1}$ and $\mathrm{I}_{\mathrm{K}, \mathrm{ACh}}$ ). The $\mathrm{I}_{\mathrm{Kur}}$ and $\mathrm{I}_{\mathrm{K}, \mathrm{ACh}}$ currents are predominantly expressed in the atria, thereby providing potential atrial-specific therapeutic targets.

$\mathrm{Ca}^{2+}$ entry through the L-type $\mathrm{Ca}^{2+}$-channel activates $\mathrm{Ca}^{2+}$ induced $\mathrm{Ca}^{2+}$-release from the sarcoplasmic reticulum (SR) through type-2 ryanodine receptor channels (RyR2), producing the systolic $\mathrm{Ca}^{2+}$-transient responsible for initiating contraction of atrial cardiomyocytes (Bers, 2002). In addition, inositol 
1,4,5-triphosphate $\left(\mathrm{IP}_{3}\right)$-receptor-mediated $\mathrm{Ca}^{2+}$-release may contribute to $\mathrm{Ca}^{2+}$-induced $\mathrm{Ca}^{2+}$-release by activating neighboring RyR2, although direct $\mathrm{IP}_{3}$-receptor-mediated activation of NCX1 has also been described recently (Dobrev and Nattel, 2008; Roderick and Knollmann, 2013).

Structural differences between atrial and ventricular cardiomyocytes may further contribute to a unique atrial $\mathrm{Ca}^{2+}$-handling profile. Isolated atrial cardiomyocytes generally have a less well-developed T-tubular network than ventricular cardiomyocytes. However, cardiomyocytes of certain species including humans, sheep, goats, cows, and horses do have more T-tubules than those from rodents (Dibb et al., 2009; Lenaerts et al., 2009; Richards et al., 2011). At least in sheep, this T-tubular system contributes to a more uniform, ventricular-like, $\mathrm{Ca}^{2+}$-induced $\mathrm{Ca}^{2+}$-release (Dibb et al., 2009). Although a small T-tubular system is present in human atrial myocytes, it shows some variability depending on region and cardiomyocyte size (Trafford et al., 2013). Moreover, this T-tubular system can be remodeled by cardiac disease including AF (Lenaerts et al., 2009). In atrial cardiomyocytes with a less well-developed T-tubular structure, $\mathrm{Ca}^{2+}$-induced $\mathrm{Ca}^{2+}$-release starts at the plasma membrane and propagates slowly toward the cell-center (Dobrev et al., 2009; Bootman et al., 2011). Relaxation occurs when $\mathrm{Ca}^{2+}$ is extruded from the cell via NCX1 and the plasmalemmal $\mathrm{Ca}^{2+}$-ATPase (PMCA), or is taken back up into the SR by the type-2a SR $\mathrm{Ca}^{2+}$-ATPase (SERCA2a). The affinity of SERCA2a for intracellular $\mathrm{Ca}^{2+}$ is largely determined by the inhibitory proteins phospholamban (PLB) and sarcolipin. The expression of sarcolipin is atrial-specific, whereas PLB is more strongly expressed in the ventricles than in the atria (Dobrev et al., 2009).

\section{ARRHYTHMOGENIC MECHANISMS IN AF}

AF can occur as a result of abnormalities in electrical impulse formation or impulse conduction (Nattel et al., 2008; Wakili et al., 2011; Heijman et al., 2014). Electrical impulse generation outside of the sinoatrial node, termed ectopic activity, can sustain AF as a driver, and can trigger reentry in a vulnerable substrate characterized by a slow and inhomogeneous conduction and short effective refractory periods. This vulnerable substrate can arise from genetic conditions, normal aging, or co-morbidities such as heart failure or hypertension (Wakili et al., 2011). Reentry can occur around anatomical obstacles or can be functional (i.e., occurring in the absence of anatomical obstacles). Reentry is considered the predominant mechanism for AF maintenance. When $\mathrm{AF}$ is maintained, atrial tachycardia-related remodeling produces electrical and structural alterations that further promote AF maintenance and stabilization, contributing to the progression toward longer-lasting AF episodes that are more difficult to treat.

At the cellular level, the effective refractory period is determined by APD and post-repolarization refractoriness. Conduction velocity is influenced by the depolarizing force through $\mathrm{I}_{\mathrm{Na}}$, and the electrical conduction between atrial cardiomyocytes is controlled by gap-junction channels as well as the structure of the atrial myocardium, notably the amount and composition of the extracellular matrix, particularly fibrosis. The cellular mechanisms of ectopic activity mainly involve early and delayed afterdepolarizations (EADs and DADs, respectively).
EADs are caused primarily by recovery from inactivation of $\mathrm{I}_{\mathrm{Ca}, \mathrm{L}}$ during excessive APD-prolongation, for example due to loss of repolarizing $\mathrm{K}^{+}$-currents. DADs are likely the most common mechanism underlying ectopic (triggered) activity and result from intracellular $\mathrm{Ca}^{2+}$-handling abnormalities. Spontaneous diastolic SR $\mathrm{Ca}^{2+}$-release events resulting from SR $\mathrm{Ca}^{2+}$-overload or intrinsic RyR2-dysfunction can activate NCX1, resulting in a transient-inward current that depolarizes the membrane potential as $\mathrm{Ca}^{2+}$ is extruded from the atrial cardiomyocyte (Dobrev and Wehrens, 2010). When the threshold for excitation is reached in a sufficient number of cardiomyocytes, an ectopic impulse is generated (Wakili et al., 2011).

\section{STRUCTURE, ACTIVATION AND TARGETS OF CaMKII}

CaMKII is a multifunctional serine/threonine protein kinase that is abundantly expressed in various tissues including the heart (Swaminathan et al., 2012). There are four CaMKII isoforms, with CaMKII $\delta$ being the most abundant in heart. CaMKII $\delta$ has a hypervariable region, giving rise to multiple splice variants, including a splice variant with a nuclear localization signal (NLS; CaMKII $\delta_{\mathrm{B}}$ ) and one without such NLS sequence $\left(\mathrm{CaMKII} \delta_{\mathrm{C}}\right)$. The latter was traditionally considered cytosolic (Swaminathan et al., 2012), although this localization is not absolute (Mishra et al., 2011). CaMKII is a holoenzyme consisting of two stacked hexameric rings of subunits. Each subunit has a catalytic domain that, under resting conditions, is inhibited by regulatory domains of neighboring subunits. When intracellular $\mathrm{Ca}^{2+}$-levels periodically rise during the cellular $\mathrm{Ca}^{2+}$. transient, $\mathrm{Ca}^{2+}$ binds to calmodulin and activates CaMKII by binding to the regulatory domain (Swaminathan et al., 2012). CaMKII subunits can auto-phosphorylate Thr287 on neighboring subunits, thereby hindering the re-association of the catalytic and regulatory domains, producing sustained $\mathrm{Ca}^{2+}$-independent activation. This mechanism makes CaMKII activation strongly heart rate-dependent, with accumulating activity at faster rates. Furthermore, CaMKII can show $\mathrm{Ca}^{2+}$-independent activation following oxidation of Met281/282 by reactive oxygen species (Erickson et al., 2008), via O-linked glycosylation of Ser280 by O-linked $\mathrm{N}$-acetylglucosamine (Erickson et al., 2013), and via NO-dependent nitrosylation of Cys116, Cys273, or Cys290, the exact residue being at present unknown (Gutierrez et al., 2013). In contrast, phosphorylation of Thr306/307 promotes CaMKII inactivation by reducing the binding of $\mathrm{Ca}^{2+} /$ calmodulin complexes (Colbran, 1993).

CaMKII can phosphorylate multiple substrates in atrial cardiomyocytes (Figure 1). CaMKII-dependent phosphorylation of L-type $\mathrm{Ca}^{2+}$-channels produces high-activity mode- 2 gating resulting in increased open probability of $\mathrm{I}_{\mathrm{Ca}, \mathrm{L}}$, thereby augmenting the amount of $\mathrm{Ca}^{2+}$ entering the atrial cardiomyocyte. CaMKII also contributes to the increase in $\mathrm{I}_{\mathrm{Ca}, \mathrm{L}}$ following repeated depolarizing pulses (termed $\mathrm{Ca}^{2+}$-dependent $\mathrm{I}_{\mathrm{Ca}, \mathrm{L}^{-}}$ facilitation) (Swaminathan et al., 2012). CaMKII-dependent phosphorylation of Nav1.5 slows $\mathrm{I}_{\mathrm{Na}}$ inactivation and augments the non-inactivating, "late" component of $\mathrm{I}_{\mathrm{Na}}$ (Wagner et al., 2011). The Kv4.3 pore-forming subunit of $I_{\text {to }}$ is also regulated by CaMKII-dependent phosphorylation through the accessory protein SAP97, resulting in increased $\mathrm{I}_{\text {to }}$ that would tend to 
shorten APD (El-Haou et al., 2009; Wagner et al., 2009). Based on experiments involving CaMKII inhibition with an inhibitory peptide or the experimental drug KN-93, CaMKII also appears to acutely augment $\mathrm{I}_{\mathrm{K} 1}$ (Wagner et al., 2009) and $\mathrm{I}_{\mathrm{Kur}}$ (Tessier et al., 1999), thereby offsetting the APD-prolonging effects of CaMKII-dependent $\mathrm{I}_{\mathrm{Ca}, \mathrm{L}}$ and $\mathrm{I}_{\mathrm{Na}}$ phosphorylation. In addition, both PLB and sarcolipin can undergo CaMKII-dependent phosphorylation, causing disinhibition of SERCA2a and increasing SR $\mathrm{Ca}^{2+}$-reuptake (Dobrev and Wehrens, 2010). Finally, CaMKIIdependent hyperphosphorylation of Ser2814 on RyR2 increases channel open probability, augmenting SR $\mathrm{Ca}^{2+}$-release. Taken together, CaMKII plays a nodal role in the modulation of atrial cellular $\mathrm{Ca}^{2+}$-handling.

\section{$\mathrm{Ca}^{2+}$ / CaMKII DYSREGULATION IN AF MECHANISMS PROMOTING CaMKII DYSREGULATION IN AF}

CaMKII $\delta$ protein expression and activity are increased in dogs with pacing-induced atrial tachycardia remodeling (Wakili et al., 2010), goats with long-standing AF (Greiser et al., 2009), and patients with chronic AF (cAF); (Tessier et al., 1999; Neef et al., 2010; Voigt et al., 2012), suggesting that increased CaMKII function can be a consequence of AF. Activation of CaMKII appears to be regulated locally within the myocyte, since autophosphorylation of Thr287 was increased for CaMKII $\delta_{C}$ but not CaMKII $\delta_{B}$ in patients with cAF (Voigt et al., 2012). Several AFrelated conditions, including sympathetic hyperactivity, oxidative stress and atrial tachycardia per se, may promote CaMKII activation (Figure 2). High atrial-rates during AF can activate CaMKII via frequency-dependent mechanisms. In addition, neuronal autonomic dysbalance can contribute to AF initiation (Park et al., 2012) and atrial tachycardia, in turn, promotes neural remodeling including heterogeneous sympathetic hyperactivity (Jayachandran et al., 2000). Increased sympathetic activity can activate CaMKII through various pathways, including protein kinase-A (PKA)-dependent augmentation of cellular $\mathrm{Ca}^{2+}$-cycling (Grimm and Brown, 2010). In addition, PKA-independent, exchange-protein activated by cAMP (Epac) can activate CaMKII following $\beta$-adrenoceptor stimulation (Mangmool et al., 2010; Pereira et al., 2013). Moreover, $\beta 1$-adrenoceptor-activated Epac2 can promote SR Ca ${ }^{2+}$-leak via phosphorylation of RyR2-Ser2814 (Pereira et al., 2013). It has also been suggested that the Epac-mediated CaMKII activation involves phosphorylation of CaMKII-Thr287 by protein kinaseC type- $\varepsilon$ (PKC $\varepsilon$ ) (Oestreich et al., 2009) and the upregulation of $\mathrm{PKC} \varepsilon$ in $\mathrm{cAF}$ patients (Voigt et al., 2008) might contribute to increased CaMKII activity. Since PKC 8 translocation to the membrane is increased in atrial myocytes following in vitro tachypacing (Makary et al., 2011), this might promote local atrial tachycardia-dependent CaMKII stimulation, although this remains to be proven in future studies. AF is also associated with oxidative stress and oxidation of CaMKII is increased in AF patients (Purohit et al., 2013). Conversely, phosphorylation of the inhibitory Thr306/307 site is decreased in cAF patients, providing another pathway of CaMKII activation in AF (Voigt et al., 2012).

Atrial CaMKII activity is also increased in dogs with ventricular tachypacing-induced heart failure (Yeh et al., 2008), and in goats with atrial dilatation (Greiser et al., 2009), suggesting that
CaMKII can be activated by AF-enabling cardiac pathologies, potentially contributing to the evolution of a vulnerable substrate for AF initiation. Similarly, increased body-mass index and diabetes are AF risk-factors (Dublin et al., 2006) that may further promote CaMKII activation via O-linked glycosylation in response to hyperglycaemia (Erickson et al., 2013). Thus, CaMKII activation is multifactorial, resulting from AF itself, as well as from AF-enabling risk factors and diseases (Figure 2).

\section{ROLE OF CaMKII IN ECTOPIC ACTIVITY}

CaMKII has been shown to promote EADs in ventricular cardiomyocytes (Qi et al., 2009), which can produce ectopic (triggered) activity. CaMKII-dependent phosphorylation of $\mathrm{I}_{\mathrm{Ca}, \mathrm{L}}$ slows $\mathrm{I}_{\mathrm{Ca}, \mathrm{L}}$ inactivation, increasing the $\mathrm{I}_{\mathrm{Ca}, \mathrm{L}}$ window current that plays a major role in the generation of EADs (Qi et al., 2009). In addition, the APD-prolonging effects of CaMKII-dependent phosphorylation of $\mathrm{I}_{\mathrm{Na}}$, increasing $\mathrm{I}_{\mathrm{Na}}$, late, could further promote the occurrence of EADs and ectopic activity (Wagner et al., 2011). However, since most forms of AF are generally associated with abbreviated APD, the relevance of such EADs may be lower in atrial compared to ventricular arrhythmogenesis. On the other hand, EADs can also arise from $\mathrm{Ca}^{2+}$-handling abnormalities that activate depolarizing NCX-current (late phase-3 EADs), which have been implicated in the initiation of AF in some animal models (Burashnikov and Antzelevitch, 2003; Patterson et al., 2006).

$\mathrm{Ca}^{2+}$-handling abnormalities can also cause DADs and ectopic (triggered) activity, promoting AF initiation. Genetic mouse models have revealed that intrinsic RyR2-dysfunction is sufficient to increase the susceptibility to pacing-induced AF, as reviewed in (Dobrev et al., 2011). Mice with gain-of-function RyR2 mutations causing catecholaminergic polymorphic ventricular tachycardia (CPVT), and mice lacking the RyR2-stabilizing subunit FKBP12.6, develop $\mathrm{Ca}^{2+}$-handling abnormalities including increased SR $\mathrm{Ca}^{2+}$-leak and spontaneous $\mathrm{SR} \mathrm{Ca}^{2+}$-release events (i.e., sparks, waves). These mice also have an increased susceptibility to pacing-induced AF (Sood et al., 2008; Chelu et al., 2009; Shan et al., 2012). Rapid-pacing activates CaMKII and increases CaMKII-dependent RyR2 and PLB phosphorylation. Genetic and pharmacological CaMKII inhibition normalized the susceptibility to pacing-induced AF in mice with a CPVT mutation in RyR2 (Chelu et al., 2009). Of note, selective genetic inhibition of CaMKII-dependent RyR2-hyperphosphorylation (RyR2-Ser2814Ala) also reduced the incidence of rapid-pacinginduced $\mathrm{AF}$ in mice where a vulnerable substrate was created using stimulation with the muscarinic-receptor agonist carbachol, and pacing-induced AF in mice deficient of FKBP12.6 (Chelu et al., 2009; Li et al., 2012), strongly suggesting that CaMKII-dependent RyR2 hyperphosphorylation and associated $\mathrm{Ca}^{2+}$-handling abnormalities are critical AF-promoting factors (Dobrev et al., 2011). In addition, recent work has identified calmodulin as a direct regulator of RyR2 that stabilizes SR $\mathrm{Ca}^{2+}$. release (Yang et al., 2014). Although overall calmodulin levels are increased in cAF patients (Voigt et al., 2012), a reduced affinity between RyR2 and calmodulin, as observed in heart failure (Yang et al., 2014), could potentially contribute to RyR2 dysfunction in AF. 


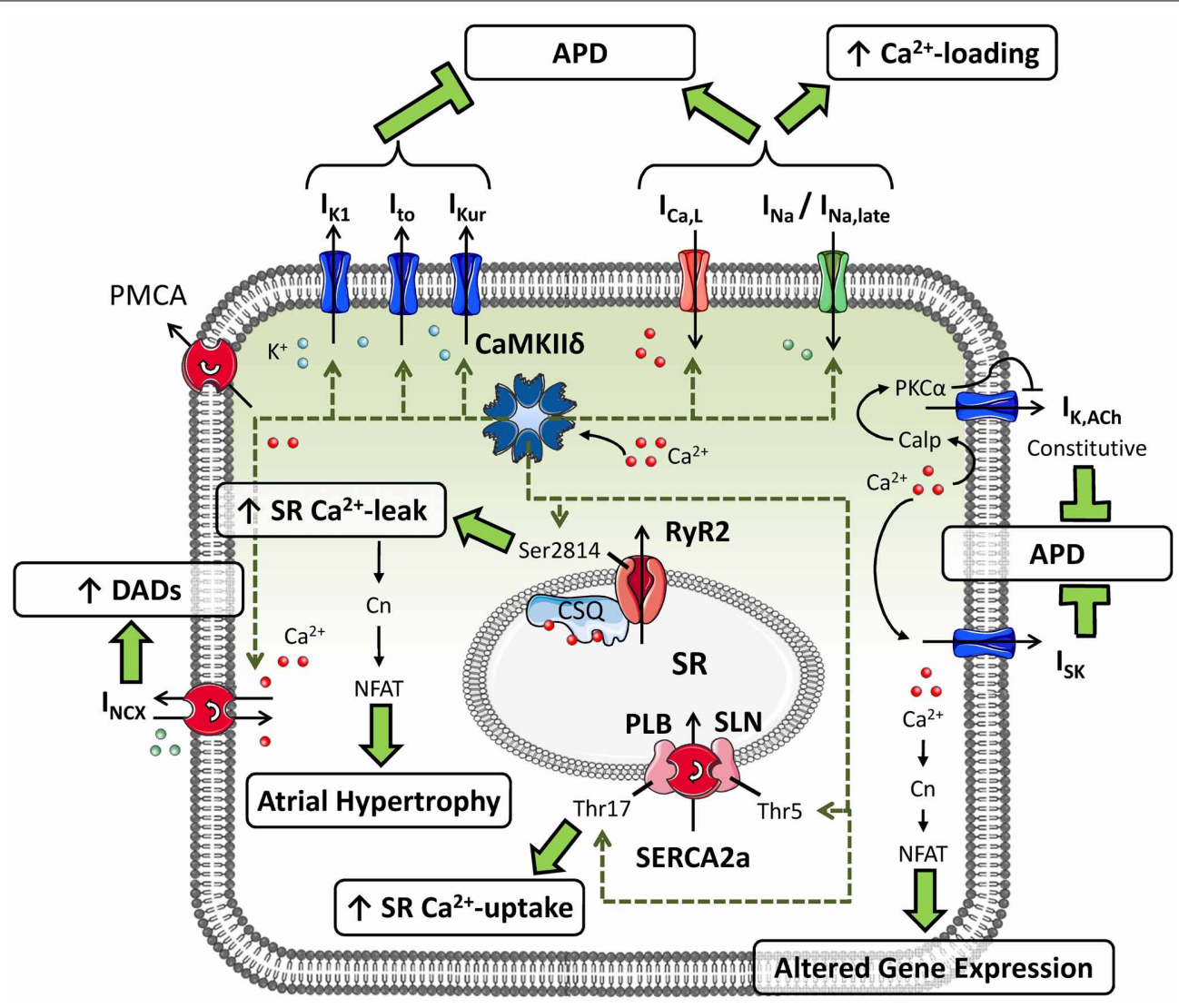

FIGURE 1 | Putative substrates for CaMKII-dependent phosphorylation in atrial cardiomyocytes and their consequences for atrial cellular electrophysiology and $\mathrm{Ca}^{2+}$-handling. CaMKII can phosphorylate the transient-outward $\mathrm{K}^{+}$-current $\left(\mathrm{I}_{\text {to }}\right)$, inward-rectifier $\mathrm{K}^{+}$-current $\left(\mathrm{I}_{\mathrm{K} 1}\right)$ and ultra-rapid delayed-rectifier $\mathrm{K}^{+}$-current $\left(\mathrm{I}_{\mathrm{Kur}}\right)$, augmenting their functions and shortening action potential duration (APD). Phosphorylation of L-type $\mathrm{Ca}^{2+}$-current $\left(\mathrm{I}_{\mathrm{Ca}, \mathrm{L}}\right)$ and $\mathrm{Na}^{+}$-current $\left(\mathrm{I}_{\mathrm{Na}}\right.$; resulting in an increased late component: $I_{\text {Na,late }}$ by CaMKII increases intracellular $\mathrm{Ca}^{2+}$ levels and prolongs APD. CaMKII-dependent phosphorylation of phospholamban (PLB) and sarcolipin (SLN) increases sarcoplasmic reticulum (SR) $\mathrm{Ca}^{2+}$-uptake, whereas phosphorylation of type-2 ryanodine-receptor channels (RyR2) promotes diastolic SR Ca ${ }^{2+}{ }_{-}$-leak. CaMKII-dependent increases in expression of $\mathrm{Na}^{+} / \mathrm{Ca}^{2+}$-exchanger type-1 (NCX1) augment NCX-current $\left(I_{\mathrm{NCX}}\right)$, promoting the occurrence of delayed afterdepolarizations (DADs). In addition, $\mathrm{Ca}^{2+}$-handling abnormalities can activate small-conductance $\mathrm{Ca}^{2+}$-activated $\mathrm{K}^{+}$-currents $\left(\mathrm{I}_{\mathrm{SK}}\right)$ and agonist-independent "constitutive" $\mathrm{I}_{\mathrm{K}, \mathrm{ACh}}$, shortening $A P D$, and promote altered gene expression via the $\mathrm{Ca}^{2+}$-dependent phosphatase calcineurin $(\mathrm{Cn})$.
Atrial cardiomyocytes from cAF patients have unaltered RyR2 protein expression levels and SR $\mathrm{Ca}^{2+}$-load (Voigt et al., 2012). However, they exhibit CaMKII-dependent RyR2hyperphosphorylation that increases RyR2 open probability and augments SR $\mathrm{Ca}^{2+}$-leak and spontaneous diastolic $\mathrm{Ca}^{2+}$-release events. The enhanced SR $\mathrm{Ca}^{2+}$ leak results in enhanced DADs and cellular triggered activity and can be blocked using CaMKII inhibitors, thus supporting an important proarrhythmic role for these CaMKII-dependent $\mathrm{Ca}^{2+}$-handling abnormalities in human AF (Voigt et al., 2012). In addition, cAF patients had significantly reduced levels of RyR2-stabilizing FKBP12.6 subunits (Vest et al., 2005) and larger transient-inward currents/depolarizations for a given SR $\mathrm{Ca}^{2+}$-release. The latter is in part mediated by increased NCX1 mRNA (Gaborit et al., 2005) and protein expression levels (Schotten et al., 2002; El-Armouche et al., 2006; Voigt et al., 2012) in cAF patients. There is evidence that CaMKII can upregulate NCX1 transcription following $\beta$-adrenoceptor stimulation (Mani et al., 2010), suggesting that
CaMKII could also be involved in the increased NCX1 expression in AF. Although atrial cardiomyocytes from paroxysmal $\mathrm{AF}$ (pAF) patients also have increased SR $\mathrm{Ca}^{2+}$-leak, spontaneous SR $\mathrm{Ca}^{2+}$-release events and DADs, these effects appear to be CaMKII-independent, since CaMKII expression and Thr287 autophosphorylation were not changed in pAF patients (Voigt et al., 2014). Similarly, CaMKII-dependent PLB and RyR2 phosphorylation, as well as NCX1 expression were also unaltered in pAF patients. However, RyR2 expression and RyR2 single-channel open-probability were increased and SR $\mathrm{Ca}^{2+}$-load was larger in pAF, likely due to PKA-dependent PLB hyperphosphorylation (Voigt et al., 2014). Computational modeling showed that both increased SR $\mathrm{Ca}^{2+}$-load and RyR2 dysregulation contribute to the spontaneous diastolic SR Ca ${ }^{2+}$-release events in cardiomyocytes from pAF patients. Thus, although SR $\mathrm{Ca}^{2+}$-handling abnormalities appear a central element in experimental and human AF, the underlying molecular mechanisms are complex. In addition, it is likely that the proarrhythmic consequences of $\mathrm{Ca}^{2+}$-handling 


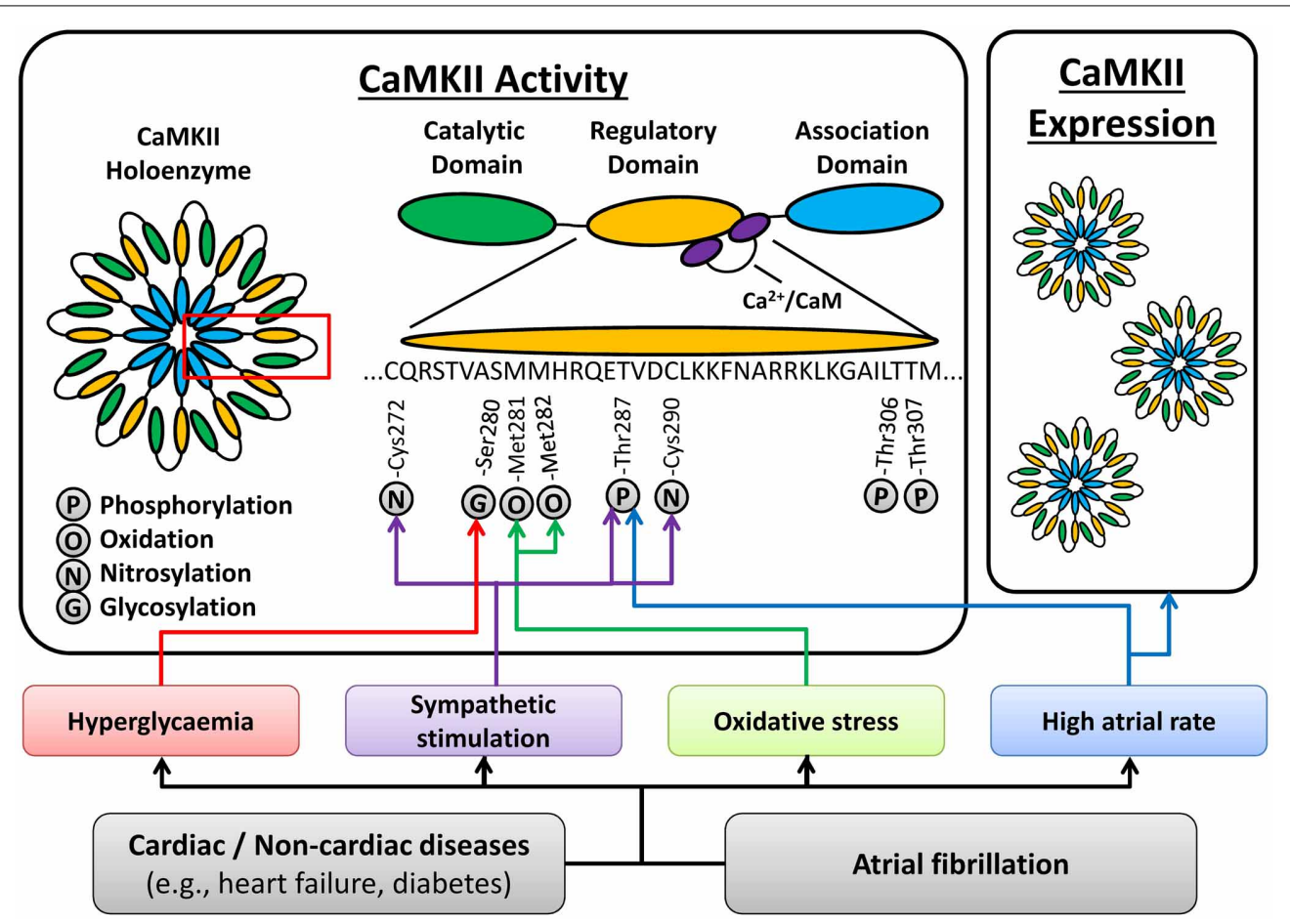

FIGURE 2 | Atrial fibrillation (AF)-related mechanisms promoting CaMKII activation. AF-promoting conditions and/or AF itself can activate CaMKII via high atrial rates, oxidative stress, sympathetic hyperactivity, and hyperglycaemia, resulting in post-translational modifications (phosphorylation, oxidation, nitrosylation and glycosylation) of various residues in the regulatory domain of CaMKII. In addition, AF is associated with an increased total expression of the CaMKII holoenzyme. See text for details. abnormalities are distinct for different types of AF (Figure 3). Whereas $\mathrm{Ca}^{2+}$-mediated triggered activity is a likely candidate for the re-initiation of AF episodes in pAF patients, its relevance for patients with long-standing persistent AF is incompletely understood. In persistent $\mathrm{AF}$ forms, $\mathrm{Ca}^{2+}$-dependent evolution and progression of atrial remodeling may play a prominent role in arrhythmia maintenance and stabilization (as discussed below).

\section{ROLE OF CaMKII IN REENTRY-PROMOTING REMODELING}

$\mathrm{Ca}^{2+}$-handling abnormalities also play a role in AF-promoting reentry. APD-shortening is a hallmark feature of AF-related remodeling that facilitates the maintenance of reentrant circuits. It is largely mediated by a reduction in depolarizing $\mathrm{I}_{\mathrm{Ca}, \mathrm{L}}$ and an increase in several repolarizing $\mathrm{K}^{+}$-currents. Various mechanisms contribute to reduced $\mathrm{I}_{\mathrm{Ca}, \mathrm{L}}$ in AF (Dobrev et al., 2012). Cav1.2 expression is reduced in AF through a pathway involving the $\mathrm{Ca}^{2+}$-dependent phosphatase calcineurin and nuclear factor of activated T-cells (NFAT) (Qi et al., 2008) and increased activation of the $\mathrm{Ca}^{2+}$-dependent protease calpain promotes breakdown of $\mathrm{I}_{\mathrm{Ca}, \mathrm{L}}$ channels (Brundel et al., 2004). $\mathrm{I}_{\mathrm{Ca}, \mathrm{L}}$ phosphorylation is also reduced in AF, decreasing current amplitude, and could be due to either increased protein phosphatase activity or local reduction in CaMKII availability (Christ et al., 2004). $I_{K 1}$ is increased in cAF patients, and, together with an increase in the acetylcholine-independent "constitutive" activity of $\mathrm{I}_{\mathrm{K}, \mathrm{ACh}}$, results in an overall increase in inward-rectifier $\mathrm{K}^{+}$current that contributes to APD shortening (Dobrev et al., 2005).
$\mathrm{A} \mathrm{Ca}^{2+}$-dependent NFAT-mediated reduction in the inhibitory microRNA-26 in AF results in disinhibition of Kir2.1 expression, contributing to the increase in $\mathrm{I}_{\mathrm{K} 1}$ in cAF patients (Luo et al., 2013). Increased constitutive $I_{K, A C h}$ may also result from $\mathrm{Ca}^{2+}$-dependent calpain-mediated reduction in inhibitory $\mathrm{PKC} \alpha$ (Makary et al., 2011). Thus, the proarrhythmic increases in $I_{K 1}$ and constitutive $\mathrm{I}_{\mathrm{K}, \mathrm{ACh}}$ are partially mediated by $\mathrm{Ca}^{2+}$-dependent processes, althouth the potential involvement of CaMKII needs to be specifically addressed in future studies. Finally, the $\mathrm{Ca}^{2+}$. dependent small-conductance $(\mathrm{SK}) \mathrm{K}^{+}$-current $\left(\mathrm{I}_{\mathrm{SK}}\right)$ is upregulated in atria of CAF patients, which might contribute to APD shortening (Zhou et al., 2012), although others have reported reduced ISK in AF (Yu et al., 2012). Acute $\mathrm{Ca}^{2+}$-dependent regulation of currents such as $\mathrm{I}_{\mathrm{Na}}$, $\mathrm{I}_{\mathrm{SK}}$ or $\mathrm{I}_{\mathrm{Ca}, \mathrm{L}}$ can also contribute to beat-by-beat alterations in APD, including APD alternans and augmentation of dispersion of repolarization. These spatial and temporal repolarization heterogeneities favor unidirectional conduction block that can initiate reentry. In agreement, atrial APD alternans is emerging as a clinical index to assess the vulnerability to develop AF in patients (Lalani et al., 2013).

$\mathrm{Ca}^{2+}$-entry into atrial fibroblasts via multiple ion channels contributes to fibroblast proliferation and differentiation into collagen-secreting myofibroblasts, which promote fibrosisinduced heterogeneous conduction slowing and reentry (Yue et al., 2011). Transient-receptor potential (TRP) melastatinrelated-7 (TRPM7) and canonical-3 (TRPC3) channels are major sources of $\mathrm{Ca}^{2+}$-entry into human atrial fibroblasts (Du et al., 


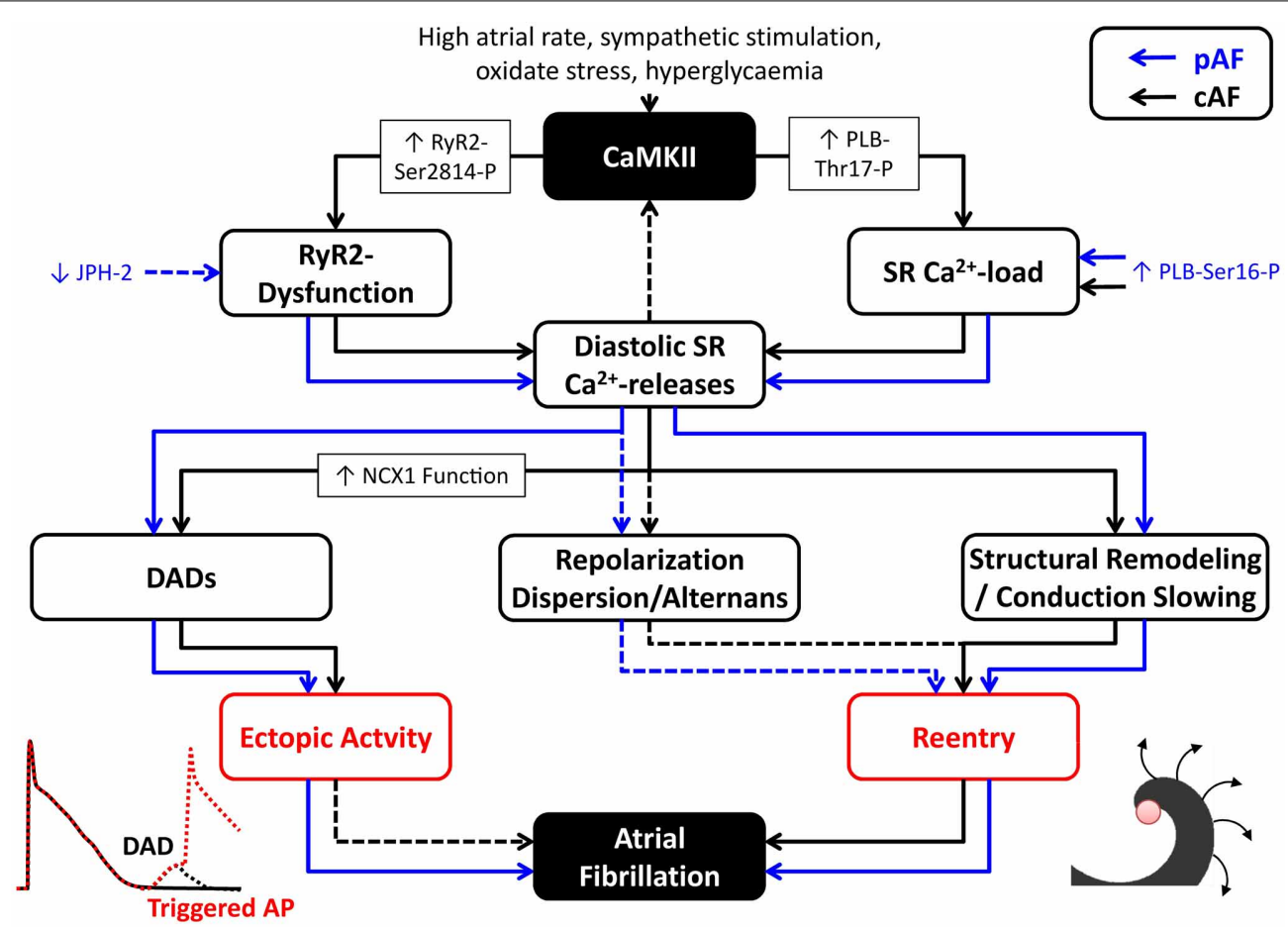

FIGURE 3 | Proarrhythmic consequences of $\mathrm{Ca}^{2+} / \mathrm{CaMKII}$ dysregulation in atrial fibrillation (AF). CaMKII activation and CaMKII-dependent phosphorylation of type-2 ryanodine-receptor (RyR2) channels (RyR2-Ser2814-P) and phospholamban (PLB-Thr17-P), as well as other factors, promote spontaneous diastolic sarcoplasmic reticulum (SR) $\mathrm{Ca}^{2+}$-release events through RyR2 dysfunction and modulation of SR $\mathrm{Ca}^{2+}$-load in patients with paroxysmal AF (pAF; blue lines) and long-standing persistent, chronic AF (cAF; black lines). SR $\mathrm{Ca}^{2+}$-leak and diastolic SR $\mathrm{Ca}^{2+}$-release events can produce delayed afterdepolarizations (DADs) that contribute to ectopic activity. In addition, they can promote reentry through local repolarization abnormalities, as well as structural remodeling and conduction velocity (CV) slowing. Influences for which the proarrhythmic roles are more speculative have been indicated with dashed lines.
2010; Harada et al., 2012). Atrial fibroblasts from AF-patients have larger TRPM7 currents and increased TRPC3 expression, and are more prone to differentiate into myofibroblasts. Knockdown of TRPM7 expression reduces basal differentiation of fibroblasts from cAF patients (Du et al., 2010). Furthermore, pharmacological inhibition of TRPC3 channels reduces AF substrate development and AF duration in dogs with electrically maintained AF (Harada et al., 2012). TRPM7-like channels are inhibited by CaMKII in hepatocytes, which may support hepatocellular survival during proliferation (Mishra et al., 2009). Moreover, $\mathrm{Ca}^{2+}$-influx through TRPC3 promotes CaMKII activation and NADPH-oxidase-mediated production of reactive oxygen species in a genetic mouse model (Kitajima et al., 2011). Thus, CaMKII could potentially act both upstream and downstream of TRP channels to alter fibroblast function in AF, although this requires confirmation in subsequent studies.

$\mathrm{Ca}^{2+}$-handling abnormalities can also promote reentry by reducing atrial conduction velocity through a reduction in $\mathrm{I}_{\mathrm{Na}}$ or direct inhibition of gap-junction channels in atrial cardiomyocytes (Heijman et al., 2013b; King et al., 2013b). The reduction in conduction velocity observed in mice with RyR2 mutations could be reproduced in wild-type mice with acute application of caffeine to increase SR $\mathrm{Ca}^{2+}$-leak, and appears to be due to both acute $\mathrm{Ca}^{2+}$-dependent inhibition of $\mathrm{I}_{\mathrm{Na}}$, as well as downregulation of Nav1.5 subunit expression under chronic conditions (King et al., 2013a). This $\mathrm{Ca}^{2+}$-dependent reduction in $\mathrm{I}_{\mathrm{Na}}$ is expected to promote reentry-mediated AF maintenance but may also reduce the likelihood of ectopic activity (Heijman et al., 2013b). At present the role of CaMKII in these reentry-promoting $\mathrm{Ca}^{2+}$-handling abnormalities is largely unknown, although it has been suggested that CaMKIIdependent phosphorylation could also reduce peak $\mathrm{I}_{\mathrm{Na}}$, particularly at fast heart rates relevant for AF (Wagner et al., 2006), which could contribute to reentry by reducing atrial conduction velocity.

Cardiac myosin-binding protein-C (cMyBPC) is a critical regulator of myofilament function (Schlossarek et al., 2011). Ser282-phosphorylation of cMyBPC is decreased in dogs with pacing-induced atrial tachycardia remodeling (Wakili et al., 2010), in dogs with ventricular tachypacing-induced heart failure (Yeh et al., 2008), goats with long-standing AF or atrial dilatation (Greiser et al., 2009), and in cAF patients (Tessier et al., 1999; Neef et al., 2010; Voigt et al., 2012). Although there is indirect evidence that this could be due to increased local dephosphorylation by phosphatases, reduced local CaMKIIdependent phosphorylation of Ser282 could also be involved. In addition, contractile dysfunction is promoted by activation of $\mathrm{Ca}^{2+}$-dependent proteases. Together, contractile dysfunction and 
associated atrial dilatation result in a larger vulnerable substrate, promoting reentrant arrhythmias (De Jong et al., 2011).

Accumulating evidence suggests that CaMKII-dependent RyR2-hyperphosphorylation and the related $\mathrm{SR} \mathrm{Ca}^{2+}$-leak play an important role in AF-promoting structural remodeling. Mice with transgenic overexpression of the transcriptional repressor CREM-Ib $\Delta \mathrm{C}-\mathrm{X}$ in cardiomyocytes (CREM mice) develop age-dependent progression from spontaneous atrial ectopy to paroxysmal and long-lasting AF episodes (Li et al., 2014). The development of spontaneous AF episodes is preceded by $\mathrm{Ca}^{2+}$-handling abnormalities and atrial enlargement. Genetic inhibition of CaMKII-dependent RyR2 phosphorylation (RyR2Ser2814Ala) in CREM mice prevents $\mathrm{Ca}^{2+}$-handling abnormalities and spontaneous AF, as well as atrial dilatation and conduction abnormalities (Li et al., 2014). Thus, CaMKII-dependent RyR2-dysregulation not only contributes to ectopic (triggered) activity, but also drives a progressive development of an AF substrate (Figure 3), promoting atrial hypertrophy and dilatation, and AF progression (Li et al., 2014). These studies suggest the interesting possibility that the progression of $\mathrm{AF}$ might be inhibited by targeted treatment of CaMKII or SR $\mathrm{Ca}^{2+}$-leak via RyR2. Future studies in mice and large animal models are required to confirm this concept, since the pathophysiological mechanisms and the importance of CaMKII likely vary for different species and experimental AF models, as well as for different forms of clinical AF.

\section{CaMKII DYSREGULATION AND $\mathrm{Ca}^{2+}$-HANDLING ABNORMALITIES AS THERAPEUTIC TARGETS IN AF}

The central role of $\mathrm{Ca}^{2+}$-handling abnormalities in AFpathophysiology suggests their potential as antiarrhythmic targets. Stabilization of RyR2 has emerged as a viable approach to normalize $\mathrm{Ca}^{2+}$-handling abnormalities. Several currently-available antiarrhythmic drugs, including the class-Ic $\mathrm{Na}^{+}$-channel blocker flecainide (Hilliard et al., 2010), the $\beta$-adrenoceptor blocker carvedilol (Zhou et al., 2011), and the antianginal drug ranolazine (Parikh et al., 2012), directly bind and inhibit RyR2 channels. Indeed, flecainide has been successfully employed in other $\mathrm{Ca}^{2+}$-dependent arrhythmias such as CPVT (Van Der Werf et al., 2011). However, flecainide also inhibits atrial $\mathrm{K}^{+}$-currents like $\mathrm{I}_{\mathrm{K}, \mathrm{ACh}}$ (Voigt et al., 2010), which might contribute to its anti-AF efficacy. More specific RyR2 inhibitors are currently being evaluated in clinical studies (Dobrev et al., 2012).

Inhibition of CaMKII or elimination of CaMKII-dependent RyR2-phosphorylation has proven antiarrhythmic in mouse models of AF and has shown beneficial effects in atrial cardiomyocytes from cAF patients (Chelu et al., 2009; Li et al., 2012; Voigt et al., 2012). However, given the importance of CaMKII in various physiological processes, systemic CaMKII inhibition could have various undesirable side effects, including reduced fertility and impaired memory (Backs et al., 2010; Halt et al., 2012). Moreover, since CaMKII expression/autophosphorylation and CaMKII-dependent phosphorylation of RyR2 and PLB are not increased in pAF patients (Voigt et al., 2014), it is unclear whether CaMKII inhibition would be beneficial for this group of patients. Nonetheless, it appears likely that localized CaMKII inhibition could be a promising antiarrhythmic strategy for appropriatelyselected AF patients. Future animal studies and clinical trials will be needed to determine which groups of $\mathrm{AF}$ patients are most likely to benefit from CaMKII inhibition. Local inhibition of CaMKII might be possible through inhibition of specific CaMKII-isoforms and splice variants, or by modulating different CaMKII-targeting proteins. Another potential avenue could be the modulation of microRNAs. Injection of complementary "antagomirs" to reduce the activity of certain microRNAs or overexpression of microRNAs has proven beneficial in a variety of experimental models, as reviewed in (Kumarswamy and Thum, 2013). Recent work has shown that CaMKII $\delta$ expression is repressed by microRNA-145 (Cha et al., 2013) and microRNA30b-5p (He et al., 2013). Increasing the levels of these microRNAs in the heart might, therefore, be an option to inhibit CaMKII.

\section{CONCLUSIONS}

$\mathrm{Ca}^{2+}$-handling abnormalities promote both focal ectopic (triggered) activity and reentry that contribute to AF initiation and maintenance. The expected increase in the incidence of $\mathrm{AF}$ and the limited efficacy and safety of currently available antiarrhythmic drugs, make a better understanding of these AF-modulating processes critical for the development of improved therapeutic strategies. $\mathrm{Ca}^{2+}$-handling abnormalities provide a novel set of potential antiarrhythmic targets for the treatment of AF. However, due to the multitude of etiologies and complexity of mechanisms underlying clinical AF, it is likely that tailored therapeutic strategies for specific groups of patients that target multiple pathophysiological processes will be necessary. Cardiac-specific inhibition of CaMKII could be a promising therapeutic strategy for certain groups of AF patients.

\section{FUNDING}

The authors' work is supported by the European-North American Atrial Fibrillation Research Alliance (07CVD03 to Dobromir Dobrev) and the Alliance for Calmodulin Kinase Signaling in Heart Disease (08CVD01, to Xander H. T. Wehrens) grants of Fondation Leducq, the European Network for Translational Research in Atrial Fibrillation (EUTRAF; 261057, to Dobromir Dobrev), the German Federal Ministry of Education and Research through the DZHK (German Center for Cardiovascular Research, to Dobromir Dobrev), the American Heart Association (13EIA14560061 to Xander H. T. Wehrens), Muscular Dystrophy Association (186530), and National Institutes of Health grants HL089598, HL091947, and HL117641 (to Xander H. T. Wehrens).

\section{REFERENCES}

Backs, J., Stein, P., Backs, T., Duncan, F. E., Grueter, C. E., McAnally, J., et al. (2010). The $\gamma$ isoform of CaM kinase II controls mouse egg activation by regulating cell cycle resumption. Proc. Natl. Acad. Sci. U.S.A. 107, 81-86. doi: 10.1073/pnas.0912658106

Bers, D. M. (2002). Cardiac excitation-contraction coupling. Nature 415, 198-205. doi: $10.1038 / 415198$ a

Bootman, M. D., Smyrnias, I., Thul, R., Coombes, S., and Roderick, H. L. (2011). Atrial cardiomyocyte calcium signalling. Biochim. Biophys. Acta 1813, 922-934. doi: 10.1016/j.bbamcr.2011.01.030

Brundel, B. J., Kampinga, H. H., and Henning, R. H. (2004). Calpain inhibition prevents pacing-induced cellular remodeling in a HL-1 myocyte model for atrial fibrillation. Cardiovasc. Res. 62, 521-528. doi: 10.1016/j.cardiores.2004.02.007 
Burashnikov, A., and Antzelevitch, C. (2003). Reinduction of atrial fibrillation immediately after termination of the arrhythmia is mediated by late phase 3 early afterdepolarization-induced triggered activity. Circulation 107, 2355-2360. doi: 10.1161/01.CIR.0000065578.00869.7C

Camm, A. J., Lip, G. Y., De Caterina, R., Savelieva, I., Atar, D., Hohnloser, S. H., et al. (2012). 2012 focused update of the ESC Guidelines for the management of atrial fibrillation: an update of the 2010 ESC Guidelines for the management of atrial fibrillation. developed with the special contribution of the European Heart Rhythm Association. Eur. Heart J. 33, 2719-2747. doi: 10.1093/eurheartj/ehs253

Camm, J. (2012). Antiarrhythmic drugs for the maintenance of sinus rhythm: risks and benefits. Int. J. Cardiol. 155, 362-371. doi: 10.1016/j.ijcard.2011.06.012

Cha, M. J., Jang, J. K., Ham, O., Song, B. W., Lee, S. Y., Lee, C. Y., et al. (2013). MicroRNA-145 suppresses ROS-induced $\mathrm{Ca}^{2+}$ overload of cardiomyocytes by targeting CaMKII $\delta$. Biochem. Biophys. Res. Commun. 435, 720-726. doi: 10.1016/j.bbrc.2013.05.050

Chelu, M. G., Sarma, S., Sood, S., Wang, S., Van Oort, R. J., Skapura, D. G., et al. (2009). Calmodulin kinase II-mediated sarcoplasmic reticulum $\mathrm{Ca}^{2+}$ leak promotes atrial fibrillation in mice. J. Clin. Invest. 119, 1940-1951. doi: 10.1172/JCI37059

Christ, T., Boknik, P., Wohrl, S., Wettwer, E., Graf, E. M., Bosch, R. F., et al. (2004). L-type $\mathrm{Ca}^{2+}$ current downregulation in chronic human atrial fibrillation is associated with increased activity of protein phosphatases. Circulation 110, 2651-2657. doi: 10.1161/01.CIR.0000145659.80212.6A

Chugh, S. S., Havmoeller, R., Narayanan, K., Singh, D., Rienstra, M., Benjamin, E. J., et al. (2013). Worldwide epidemiology of atrial fibrillation: a global burden of disease 2010 study. Circulation 129, 837-847. doi: 10.1161/CIRCULATIONAHA.113.005119

Colbran, R. J. (1993). Inactivation of $\mathrm{Ca}^{2+} /$ calmodulin-dependent protein kinase II by basal autophosphorylation. J. Biol. Chem. 268, 7163-7170.

De Jong, A. M., Maass, A. H., Oberdorf-Maass, S. U., Van Veldhuisen, D. J., Van Gilst, W. H., and Van Gelder, I. C. (2011). Mechanisms of atrial structural changes caused by stretch occurring before and during early atrial fibrillation. Cardiovasc. Res. 89, 754-765. doi: 10.1093/cvr/cvq357

Dibb, K. M., Clarke, J. D., Horn, M. A., Richards, M. A., Graham, H. K., Eisner, D. A., et al. (2009). Characterization of an extensive transverse tubular network in sheep atrial myocytes and its depletion in heart failure. Circ. Heart Fail. 2, 482-489. doi: 10.1161/CIRCHEARTFAILURE.109.852228

Dobrev, D., Carlsson, L., and Nattel, S. (2012). Novel molecular targets for atrial fibrillation therapy. Nat. Rev. Drug Discov. 11, 275-291. doi: 10.1038/nrd3682

Dobrev, D., Friedrich, A., Voigt, N., Jost, N., Wettwer, E., Christ, T., et al. (2005). The $G$ protein-gated potassium current $I_{K, A C h}$ is constitutively active in patients with chronic atrial fibrillation. Circulation 112, 3697-3706. doi: 10.1161/CIRCULATIONAHA.105.575332

Dobrev, D., and Nattel, S. (2008). Calcium handling abnormalities in atrial fibrillation as a target for innovative therapeutics. J. Cardiovasc. Pharmacol. 52, 293-299. doi: 10.1097/FJC.0b013e318171924d

Dobrev, D., and Ravens, U. (2003). Remodeling of cardiomyocyte ion channels in human atrial fibrillation. Basic Res. Cardiol. 98, 137-148. doi: 10.1007/s00395003-0409-8

Dobrev, D., Teos, L. Y., and Lederer, W. J. (2009). Unique atrial myocyte $\mathrm{Ca}^{2+}$ signaling. J. Mol. Cell. Cardiol. 46, 448-451. doi: 10.1016/j.yjmcc.2008.12.004

Dobrev, D., Voigt, N., and Wehrens, X. H. (2011). The ryanodine receptor channel as a molecular motif in atrial fibrillation: pathophysiological and therapeutic implications. Cardiovasc. Res. 89, 734-743. doi: 10.1093/cvr/cvq324

Dobrev, D., and Wehrens, X. H. (2010). Calmodulin kinase II, sarcoplasmic reticulum $\mathrm{Ca}^{2+}$ leak, and atrial fibrillation. Trends Cardiovasc. Med. 20, 30-34. doi: 10.1016/j.tcm.2010.03.004

Du, J., Xie, J., Zhang, Z., Tsujikawa, H., Fusco, D., Silverman, D., et al. (2010). TRPM7-mediated $\mathrm{Ca}^{2+}$ signals confer fibrogenesis in human atrial fibrillation. Circ. Res. 106, 992-1003. doi: 10.1161/CIRCRESAHA.109.206771

Dublin, S., French, B., Glazer, N. L., Wiggins, K. L., Lumley, T., Psaty, B. M., et al. (2006). Risk of new-onset atrial fibrillation in relation to body mass index. Arch. Intern. Med. 166, 2322-2328. doi: 10.1001/archinte.166.21.2322

El-Armouche, A., Boknik, P., Eschenhagen, T., Carrier, L., Knaut, M., Ravens, U., et al. (2006). Molecular determinants of altered $\mathrm{Ca}^{2+}$ handling in human chronic atrial fibrillation. Circulation 114, 670-680. doi: 10.1161/CIRCULATIONAHA.106.636845

El-Haou, S., Balse, E., Neyroud, N., Dilanian, G., Gavillet, B., Abriel, H., et al. (2009). Kv4 potassium channels form a tripartite complex with the anchoring protein SAP97 and CaMKII in cardiac myocytes. Circ. Res. 104, 758-769. doi: 10.1161/CIRCRESAHA.108.191007

Erickson, J. R., Joiner, M. L., Guan, X., Kutschke, W., Yang, J., Oddis, C. V., et al. (2008). A dynamic pathway for calcium-independent activation of CaMKII by methionine oxidation. Cell 133, 462-474. doi: 10.1016/j.cell.2008.02.048

Erickson, J. R., Pereira, L., Wang, L., Han, G., Ferguson, A., Dao, K., et al. (2013). Diabetic hyperglycaemia activates CaMKII and arrhythmias by O-linked glycosylation. Nature 502, 372-376. doi: 10.1038/nature12537

Gaborit, N., Steenman, M., Lamirault, G., Le Meur, N., Le Bouter, S., Lande, G., et al. (2005). Human atrial ion channel and transporter subunit geneexpression remodeling associated with valvular heart disease and atrial fibrillation. Circulation 112, 471-481. doi: 10.1161/CIRCULATIONAHA.104.506857

Greiser, M., Neuberger, H. R., Harks, E., El-Armouche, A., Boknik, P., De Haan, S., et al. (2009). Distinct contractile and molecular differences between two goat models of atrial dysfunction: AV block-induced atrial dilatation and atrial fibrillation. J. Mol. Cell. Cardiol. 46, 385-394. doi: 10.1016/j.yjmcc.2008.11.012

Grimm, M., and Brown, J. H. (2010). Beta-adrenergic receptor signaling in the heart: role of CaMKII. J. Mol. Cell. Cardiol. 48, 322-330. doi: 10.1016/j.yjmcc.2009.10.016

Gutierrez, D. A., Fernandez-Tenorio, M., Ogrodnik, J., and Niggli, E. (2013). NO-dependent CaMKII activation during $\beta$-adrenergic stimulation of cardiac muscle. Cardiovasc. Res. 100, 392-401. doi: 10.1093/cvr/cvt201

Halt, A. R., Dallapiazza, R. F., Zhou, Y., Stein, I. S., Qian, H., Juntti, S., et al. (2012). CaMKII binding to GluN2B is critical during memory consolidation. EMBO J. 31, 1203-1216. doi: 10.1038/emboj.2011.482

Harada, M., Luo, X., Qi, X. Y., Tadevosyan, A., Maguy, A., Ordog, B., et al. (2012). Transient receptor potential canonical-3 channel-dependent fibroblast regulation in atrial fibrillation. Circulation 126, 2051-2064. doi: 10.1161/CIRCULATIONAHA.112.121830

He, J., Jiang, S., Li, F. L., Zhao, X. J., Chu, E. F., Sun, M. N., et al. (2013). MicroRNA$30 \mathrm{~b}-5 \mathrm{p}$ is involved in the regulation of cardiac hypertrophy by targeting CaMKIII. J. Investig. Med. 61, 604-612. doi: 10.231/JIM.0b013e3182819ac6

Heijman, J., Voigt, N., and Dobrev, D. (2013a). New directions in antiarrhythmic drug therapy for atrial fibrillation. Future Cardiol. 9, 71-88. doi: $10.2217 / \mathrm{fca} .12 .78$

Heijman, J., Voigt, N., Nattel, S., and Dobrev, D. (2012). Calcium handling and atrial fibrillation. Wien. Med. Wochenschr. 162, 287-291. doi: 10.1007/s10354012-0109-9

Heijman, J., Voigt, N., Nattel, S., and Dobrev, D. (2014). Compendium: cellular and molecular electrophysiology of atrial fibrillation initiation, maintenance and progression. Circ. Res. doi: 10.1161/CIRCRESAHA.113.302226. [Epub ahead of print].

Heijman, J., Wehrens, X. H., and Dobrev, D. (2013b). Atrial arrhythmogenesis in catecholaminergic polymorphic ventricular tachycardia-is there a mechanistic link between sarcoplasmic reticulum $\mathrm{Ca}^{2+}$ leak and re-entry? Acta Physiol. (Oxf.) 207, 208-211. doi: 10.1111/apha.12038

Hilliard, F. A., Steele, D. S., Laver, D., Yang, Z., Le Marchand, S. J., Chopra, N., et al. (2010). Flecainide inhibits arrhythmogenic $\mathrm{Ca}^{2+}$ waves by open state block of ryanodine receptor $\mathrm{Ca}^{2+}$ release channels and reduction of $\mathrm{Ca}^{2+}$ spark mass. J. Mol. Cell. Cardiol. 48, 293-301. doi: 10.1016/j.yjmcc.2009.10.005

Jayachandran, J. V., Sih, H. J., Winkle, W., Zipes, D. P., Hutchins, G. D., and Olgin, J. E. (2000). Atrial fibrillation produced by prolonged rapid atrial pacing is associated with heterogeneous changes in atrial sympathetic innervation. Circulation 101, 1185-1191. doi: 10.1161/01.CIR.101.10.1185

King, J. H., Wickramarachchi, C., Kua, K., Du, Y., Jeevaratnam, K., Matthews, H. R., et al. (2013a). Loss of Nav1.5 expression and function in murine atria containing the RyR2-P2328S gain-of-function mutation. Cardiovasc. Res. 99, 751-759. doi: $10.1093 / \mathrm{cvr} / \mathrm{cvt} 141$

King, J. H., Zhang, Y., Lei, M., Grace, A. A., Huang, C. L., and Fraser, J. A. (2013b). Atrial arrhythmia, triggering events and conduction abnormalities in isolated murine RyR2-P2328S hearts. Acta Physiol. (Oxf.) 207, 308-323. doi: 10.1111/apha.12006

Kitajima, N., Watanabe, K., Morimoto, S., Sato, Y., Kiyonaka, S., Hoshijima, M., et al. (2011). TRPC3-mediated $\mathrm{Ca}^{2+}$ influx contributes to Rac1-mediated production of reactive oxygen species in MLP-deficient mouse hearts. Biochem. Biophys. Res. Commun. 409, 108-113. doi: 10.1016/j.bbrc.2011.04.124

Kumarswamy, R., and Thum, T. (2013). Non-coding RNAs in cardiac remodeling and heart failure. Circ. Res. 113, 676-689. doi: 10.1161/CIRCRESAHA.113.300226 
Lalani, G. G., Schricker, A. A., Clopton, P., Krummen, D. E., and Narayan, S. M. (2013). Frequency analysis of atrial action potential alternans: a sensitive clinical index of individual propensity to atrial fibrillation. Circ. Arrhythm. Electrophysiol. 6, 859-867. doi: 10.1161/CIRCEP.113.000204

Lenaerts, I., Bito, V., Heinzel, F. R., Driesen, R. B., Holemans, P., D’hooge, J., et al. (2009). Ultrastructural and functional remodeling of the coupling between $\mathrm{Ca}^{2+}$ influx and sarcoplasmic reticulum $\mathrm{Ca}^{2+}$ release in right atrial myocytes from experimental persistent atrial fibrillation. Circ. Res. 105, 876-885. doi: 10.1161/CIRCRESAHA.109.206276

Li, N., Chiang, D. Y., Wang, S., Wang, Q., Sun, L., Voigt, N., et al. (2014). Ryanodine-receptor mediated calcium leak drives progressive development of an atrial fibrillation substrate in a transgenic mouse model. Circulation. doi: 10.1161/CIRCULATIONAHA.113.006611. [Epub ahead of print].

Li, N., Wang, T., Wang, W., Cutler, M. J., Wang, Q., Voigt, N., et al. (2012). Inhibition of CaMKII phosphorylation of RyR2 prevents induction of atrial fibrillation in FKBP12.6 knockout mice. Circ. Res. 110, 465-470. doi: 10.1161/CIRCRESAHA.111.253229

Luo, X., Pan, Z., Shan, H., Xiao, J., Sun, X., Wang, N., et al. (2013). MicroRNA26 governs profibrillatory inward-rectifier potassium current changes in atrial fibrillation. J. Clin. Invest. 123, 1939-1951. doi: 10.1172/JCI62185

Makary, S., Voigt, N., Maguy, A., Wakili, R., Nishida, K., Harada, M., et al. (2011). Differential protein kinase $\mathrm{C}$ isoform regulation and increased constitutive activity of acetylcholine-regulated potassium channels in atrial remodeling. Circ. Res. 109, 1031-1043. doi: 10.1161/CIRCRESAHA.111.253120

Mangmool, S., Shukla, A. K., and Rockman, H. A. (2010). $\beta$-Arrestin-dependent activation of $\mathrm{Ca}^{2+} /$ calmodulin kinase II after $\beta_{1}$-adrenergic receptor stimulation. J. Cell Biol. 189, 573-587. doi: 10.1083/jcb.200911047

Mani, S. K., Egan, E. A., Addy, B. K., Grimm, M., Kasiganesan, H., Thiyagarajan, T., et al. (2010). $\beta$-Adrenergic receptor stimulated Ncxl upregulation is mediated via a CaMKII/AP-1 signaling pathway in adult cardiomyocytes. J. Mol. Cell. Cardiol. 48, 342-351. doi: 10.1016/j.yjmcc.2009.11.007

Mishra, R., Rao, V., Ta, R., Shobeiri, N., and Hill, C. E. (2009). $\mathrm{Mg}^{2+}$ - and MgATPinhibited and $\mathrm{Ca}^{2+} /$ calmodulin-sensitive TRPM7-like current in hepatoma and hepatocytes. Am. J. Physiol. Gastrointest. Liver Physiol. 297, G687-G694. doi: 10.1152/ajpgi.90683.2008

Mishra, S., Gray, C. B., Miyamoto, S., Bers, D. M., and Brown, J. H. (2011). Location matters: clarifying the concept of nuclear and cytosolic CaMKII subtypes. Circ. Res. 109, 1354-1362. doi: 10.1161/CIRCRESAHA.111.248401

Nattel, S., Burstein, B., and Dobrev, D. (2008). Atrial remodeling and atrial fibrillation: mechanisms and implications. Circ. Arrhythm. Electrophysiol. 1, 62-73. doi: 10.1161/CIRCEP.107.754564

Nattel, S., and Dobrev, D. (2012). The multidimensional role of calcium in atrial fibrillation pathophysiology: mechanistic insights and therapeutic opportunities. Eur. Heart J. 33, 1870-1877. doi: 10.1093/eurheartj/ehs079

Neef, S., Dybkova, N., Sossalla, S., Ort, K. R., Fluschnik, N., Neumann, K., et al. (2010). CaMKII-dependent diastolic SR Ca ${ }^{2+}$ leak and elevated diastolic $\mathrm{Ca}^{2+}$ levels in right atrial myocardium of patients with atrial fibrillation. Circ. Res. 106, 1134-1144. doi: 10.1161/CIRCRESAHA.109.203836

Oestreich, E. A., Malik, S., Goonasekera, S. A., Blaxall, B. C., Kelley, G. G., Dirksen, R. T., et al. (2009). Epac and phospholipase $\mathrm{C} \varepsilon$ regulate $\mathrm{Ca}^{2+}$ release in the heart by activation of protein kinase $\mathrm{C} \varepsilon$ and calcium-calmodulin kinase II. J. Biol. Chem. 284, 1514-1522. doi: 10.1074/jbc.M806994200

Parikh, A., Mantravadi, R., Kozhevnikov, D., Roche, M. A., Ye, Y., Owen, L. J., et al. (2012). Ranolazine stabilizes cardiac ryanodine receptors: a novel mechanism for the suppression of early afterdepolarization and torsades de pointes in long QT type 2. Heart Rhythm 9, 953-960. doi: 10.1016/j.hrthm.2012.01.010

Park, H. W., Shen, M. J., Lin, S. F., Fishbein, M. C., Chen, L. S., and Chen, P. S. (2012). Neural mechanisms of atrial fibrillation. Curr. Opin. Cardiol. 27, 24-28. doi: 10.1097/HCO.0b013e32834dc4e8

Patterson, E., Lazzara, R., Szabo, B., Liu, H., Tang, D., Li, Y. H., et al. (2006). Sodium-calcium exchange initiated by the $\mathrm{Ca}^{2+}$ transient: an arrhythmia trigger within pulmonary veins. J. Am. Coll. Cardiol. 47, 1196-1206. doi: 10.1016/j.jacc.2005.12.023

Pereira, L., Cheng, H., Lao, D. H., Na, L., Van Oort, R. J., Brown, J. H., et al. (2013). Epac2 mediates cardiac $\beta 1$-adrenergic-dependent sarcoplasmic reticulum $\mathrm{Ca}^{2+}$ leak and arrhythmia. Circulation 127, 913-922. doi: 10.1161/CIRCULATIONAHA.12.148619

Purohit, A., Rokita, A. G., Guan, X., Chen, B., Koval, O. M., Voigt, N., et al. (2013). Oxidized $\mathrm{Ca}^{2+} /$ calmodulin-dependent protein kinase II triggers atrial fibrillation. Circulation 128, 1748-1757. doi: 10.1161/CIRCULATIONAHA.113.003313

Qi, X., Yeh, Y. H., Chartier, D., Xiao, L., Tsuji, Y., Brundel, B. J., et al. (2009). The calcium/calmodulin/kinase system and arrhythmogenic afterdepolarizations in bradycardia-related acquired long-QT syndrome. Circ. Arrhythm. Electrophysiol. 2, 295-304. doi: 10.1161/CIRCEP.108.815654

Qi, X. Y., Yeh, Y. H., Xiao, L., Burstein, B., Maguy, A., Chartier, D., et al. (2008). Cellular signaling underlying atrial tachycardia remodeling of L-type calcium current. Circ. Res. 103, 845-854. doi: 10.1161/CIRCRESAHA.108.175463

Richards, M. A., Clarke, J. D., Saravanan, P., Voigt, N., Dobrev, D., Eisner, D. A., et al. (2011). Transverse tubules are a common feature in large mammalian atrial myocytes including human. Am. J. Physiol. Heart Circ. Physiol. 301, H1996-H2005. doi: 10.1152/ajpheart.00284.2011

Roderick, H. L., and Knollmann, B. C. (2013). Inositol 1,4,5-trisphosphate receptors: "exciting" players in cardiac excitation-contraction coupling? Circulation 128, 1273-1275. doi: 10.1161/CIRCULATIONAHA.113.005157

Schlossarek, S., Mearini, G., and Carrier, L. (2011). Cardiac myosin-binding protein $\mathrm{C}$ in hypertrophic cardiomyopathy: mechanisms and therapeutic opportunities. J. Mol. Cell. Cardiol. 50, 613-620. doi: 10.1016/j.yjmcc.2011.01.014

Schotten, U., Greiser, M., Benke, D., Buerkel, K., Ehrenteidt, B., Stellbrink, C., et al. (2002). Atrial fibrillation-induced atrial contractile dysfunction: a tachycardiomyopathy of a different sort. Cardiovasc. Res. 53, 192-201. doi: 10.1016/S0008-6363(01)00453-9

Shan, J., Xie, W., Betzenhauser, M., Reiken, S., Chen, B. X., Wronska, A., et al. (2012). Calcium leak through ryanodine receptors leads to atrial fibrillation in 3 mouse models of catecholaminergic polymorphic ventricular tachycardia. Circ. Res. 111, 708-717. doi: 10.1161/CIRCRESAHA.112.273342

Sood, S., Chelu, M. G., Van Oort, R. J., Skapura, D., Santonastasi, M., Dobrev, D., et al. (2008). Intracellular calcium leak due to FKBP12.6 deficiency in mice facilitates the inducibility of atrial fibrillation. Heart Rhythm 5, 1047-1054. doi: 10.1016/j.hrthm.2008.03.030

Swaminathan, P. D., Purohit, A., Hund, T. J., and Anderson, M. E. (2012). Calmodulin-dependent protein kinase II: linking heart failure and arrhythmias. Circ. Res. 110, 1661-1677. doi: 10.1161/CIRCRESAHA.111.243956

Tessier, S., Karczewski, P., Krause, E. G., Pansard, Y., Acar, C., Lang-Lazdunski, M., et al. (1999). Regulation of the transient outward $\mathrm{K}^{+}$current by $\mathrm{Ca}^{2+} /$ calmodulin-dependent protein kinases II in human atrial myocytes. Circ. Res. 85, 810-819. doi: 10.1161/01.RES.85.9.810

Trafford, A. W., Clarke, J. D., Richards, M. A., Eisner, D. A., and Dibb, K. M. (2013). Calcium signalling microdomains and the t-tubular system in atrial mycoytes: potential roles in cardiac disease and arrhythmias. Cardiovasc. Res. 98, 192-203. doi: $10.1093 / \mathrm{cvr} / \mathrm{cvt} 018$

Van Der Werf, C., Kannankeril, P. J., Sacher, F., Krahn, A. D., Viskin, S., Leenhardt, A., et al. (2011). Flecainide therapy reduces exercise-induced ventricular arrhythmias in patients with catecholaminergic polymorphic ventricular tachycardia. J. Am. Coll. Cardiol. 57, 2244-2254. doi: 10.1016/j.jacc.2011.01.026

Vest, J. A., Wehrens, X. H., Reiken, S. R., Lehnart, S. E., Dobrev, D., Chandra, P., et al. (2005). Defective cardiac ryanodine receptor regulation during atrial fibrillation. Circulation 111, 2025-2032. doi: 10.1161/01.CIR.0000162461.67140.4C

Voigt, N., Heijman, J., Wang, Q., Chiang, D. Y., Li, N., Karck, M., et al. (2014). Cellular and Molecular Mechanisms of Atrial Arrhythmogenesis in Patients With Paroxysmal Atrial Fibrillation. Circulation 129, 145-156. doi: 10.1161/CIRCULATIONAHA.113.006641

Voigt, N., Li, N., Wang, Q., Wang, W., Trafford, A. W., Abu-Taha, I., et al. (2012). Enhanced sarcoplasmic reticulum $\mathrm{Ca}^{2+}$ leak and increased $\mathrm{Na}^{+}-\mathrm{Ca}^{2+}$ exchanger function underlie delayed afterdepolarizations in patients with chronic atrial fibrillation. Circulation 125, 2059-2070. doi: 10.1161/CIRCULATIONAHA.111.067306

Voigt, N., Maguy, A., Yeh, Y. H., Qi, X., Ravens, U., Dobrev, D., et al. (2008). Changes in $\mathrm{I}_{\mathrm{K}, \mathrm{ACh}}$ single-channel activity with atrial tachycardia remodelling in canine atrial cardiomyocytes. Cardiovasc. Res. 77, 35-43. doi: $10.1093 / \mathrm{cvr} / \mathrm{cvm} 051$

Voigt, N., Rozmaritsa, N., Trausch, A., Zimniak, T., Christ, T., Wettwer, E., et al. (2010). Inhibition of $\mathrm{I}_{\mathrm{K}, \mathrm{ACh}}$ current may contribute to clinical efficacy of class I and class III antiarrhythmic drugs in patients with atrial fibrillation. Naunyn Schmiedebergs Arch. Pharmacol. 381, 251-259. doi: 10.1007/s00210-009-0452-6

Wagner, S., Dybkova, N., Rasenack, E. C., Jacobshagen, C., Fabritz, L., Kirchhof, P., et al. (2006). $\mathrm{Ca}^{2+} /$ calmodulin-dependent protein kinase II regulates cardiac $\mathrm{Na}^{+}$channels. J. Clin. Invest. 116, 3127-3138. doi: 10.1172/JCI26620 
Wagner, S., Hacker, E., Grandi, E., Weber, S. L., Dybkova, N., Sossalla, S., et al. (2009). Ca/calmodulin kinase II differentially modulates potassium currents. Circ. Arrhythm. Electrophysiol. 2, 285-294. doi: 10.1161/CIRCEP.108.842799

Wagner, S., Ruff, H. M., Weber, S. L., Bellmann, S., Sowa, T., Schulte, T., et al. (2011). Reactive oxygen species-activated $\mathrm{Ca} /$ calmodulin kinase II $\delta$ is required for late $\mathrm{I}_{\mathrm{Na}}$ augmentation leading to cellular $\mathrm{Na}$ and Ca overload. Circ. Res. 108, 555-565. doi: 10.1161/CIRCRESAHA.110.221911

Wakili, R., Voigt, N., Kaab, S., Dobrev, D., and Nattel, S. (2011). Recent advances in the molecular pathophysiology of atrial fibrillation. J. Clin. Invest. 121, 2955-2968. doi: 10.1172/JCI46315

Wakili, R., Yeh, Y. H., Yan Qi, X., Greiser, M., Chartier, D., Nishida, K., et al. (2010). Multiple potential molecular contributors to atrial hypocontractility caused by atrial tachycardia remodeling in dogs. Circ. Arrhythm. Electrophysiol. 3, 530-541. doi: 10.1161/CIRCEP.109.933036

Yang, Y., Guo, T., Oda, T., Chakraborty, A., Chen, L., Uchinoumi, H., et al. (2014). Cardiac myocyte Z-line calmodulin is mainly RyR2-bound, and reduction is arrhythmogenic and occurs in heart failure. Circ. Res. 114, 295-306. doi: 10.1161/CIRCRESAHA.114.302857

Yeh, Y. H., Wakili, R., Qi, X. Y., Chartier, D., Boknik, P., Kaab, S., et al. (2008). Calcium-handling abnormalities underlying atrial arrhythmogenesis and contractile dysfunction in dogs with congestive heart failure. Circ. Arrhythm. Electrophysiol. 1, 93-102. doi: 10.1161/CIRCEP.107.754788

Yu, T., Deng, C., Wu, R., Guo, H., Zheng, S., Yu, X., et al. (2012). Decreased expression of small-conductance $\mathrm{Ca}^{2+}$-activated $\mathrm{K}^{+}$channels SK1 and SK2 in human chronic atrial fibrillation. Life Sci. 90, 219-227. doi: 10.1016/j.lfs.2011.11.008

Yue, L., Xie, J., and Nattel, S. (2011). Molecular determinants of cardiac fibroblast electrical function and therapeutic implications for atrial fibrillation. Cardiovasc. Res. 89, 744-753. doi: 10.1093/cvr/cvq329
Zhou, Q., Xiao, J., Jiang, D., Wang, R., Vembaiyan, K., Wang, A., et al. (2011). Carvedilol and its new analogs suppress arrhythmogenic store overload-induced $\mathrm{Ca}^{2+}$ release. Nat. Med. 17, 1003-1009. doi: 10.1038/nm.2406

Zhou, X.-B., Voigt, N., Wieland, T., and Dobrev, D. (2012). Enhanced frequencydependent retograde trafficking of small conductance $\mathrm{Ca}^{2+}$-activated $\mathrm{K}^{+}$channels may contribute to electrical remodeling in human atrial fibrillation. Heart Rhythm 9, S319.

Zimetbaum, P. (2012). Antiarrhythmic drug therapy for atrial fibrillation. Circulation 125, 381-389. doi: 10.1161/CIRCULATIONAHA.111.019927

Conflict of Interest Statement: The authors declare that the research was conducted in the absence of any commercial or financial relationships that could be construed as a potential conflict of interest.

Received: 21 January 2014; accepted: 15 February 2014; published online: 04 March 2014.

Citation: Heijman J, Voigt N, Wehrens XHT and Dobrev D (2014) Calcium dysregulation in atrial fibrillation: the role of CaMKII. Front. Pharmacol. 5:30. doi: 10.3389/ fphar.2014.00030

This article was submitted to Pharmacology of Ion Channels and Channelopathies, a section of the journal Frontiers in Pharmacology.

Copyright (c) 2014 Heijman, Voigt, Wehrens and Dobrev. This is an open-access article distributed under the terms of the Creative Commons Attribution License (CC BY). The use, distribution or reproduction in other forums is permitted, provided the original author(s) or licensor are credited and that the original publication in this journal is cited, in accordance with accepted academic practice. No use, distribution or reproduction is permitted which does not comply with these terms. 